\title{
Study of Inducible Clindamycin Resistance in Staphylococcus aureus in a Tertiary Care Hospital
}

\author{
Javeria Firdous $^{1^{*}}$ and Basawaraj S. Patil ${ }^{2}$ \\ ${ }^{1}$ Department of Microbiology, KBN Institute of Medical Sciences, Kalaburagi, India \\ ${ }^{2}$ Department of Microbiology, M.R Medical College, Kalaburagi, India \\ *Corresponding author
}

\section{A B S T R A C T}

\section{Keywords}

Methicillin

Resistant

Staphylococcus

aureus (MRSA),

Methicillin

Sensitive

Staphylococcus

aureus (MSSA),

Inducible

clindamycin

resistance, Double

disc diffusion

method (D test)

Article Info

Accepted:

12 January 2019

Available Online:

10 February 2019

\begin{abstract}
Very few therapeutic options are available from the time of emergence of MRSA. Macrolide lincosamide streptogramin $\mathrm{B}\left(\mathrm{MSL}_{\mathrm{B}}\right)$ antibiotics can be used in such scenarios with clindamycin being the preferred agent due to its excellent pharmacokinetic properties. Staphylococcal resistance to clindamycin may be inducible (iMLSB - inducible MacrolideLincosamide Streptogramin B resistance) or constitutive. The treatment of patients harbouring $\mathrm{iMLS}_{\mathrm{B}}$ Staphylococci with clindamycin leads to the development of constitutive resistance, subsequently leading to therapeutic failure. If inducible Clindamycin resistance can be reliably detected by placing relevant disc adjacent to each other at proper distance as a routine basis in clinically significant isolates, Clindamycin can be safely and effectively used in patients with true Clindamycin susceptible strains. Objective of the study is to determine prevalence of inducible clindamycin resistance in S.aureus. 100 Staphylococcus aureus isolates collected from various clinical samples were subjected to routine antibiotic susceptibility testing and screening for Methicillin Resistance was done as per CLSI guidelines. Detection of inducible clindamycin resistance was done using Double disk diffusion test or D test. Out of 100 S. aureus (88 MRSA, 12 MSSA) isolates, prevalence of inducible clindamycin resistance was found to be 39\% (39 isolates). Inducible Clindamycin resistance was found to be higher in MRSA 40.9\% (36 MRSA isolates) as compared to MSSA 25\% (3 MSSA isolates). We conclude that whenever clindamycin is intended for $S$. aureus infection, the microbiology lab should tests the isolated organism for $\mathrm{iMLS}_{\mathrm{B}}$ by $\mathrm{D}$ test.
\end{abstract}

\section{Introduction}

In genus Staphylococci, the most virulent species is Staphylococcus aureus ${ }^{1}$. Methicillin resistance to $S$. aureus was first reported in 1961. At present MRSA is a major nosocomial pathogen worldwide ${ }^{2}$. Very few therapeutic options are available from the time of emergence of MRSA. Macrolide lincosamide streptogramin $\quad \mathrm{B} \quad \mathrm{MSL}_{\mathrm{B}}$ antibiotics can be used in such scenarios ${ }^{3}$ with clindamycin being the preferred agent due to its excellent pharmacokinetic properties ${ }^{4}$. Clindamycin can be given orally or parenterally. Food doesn't interfere with its absorption. It has wide distribution in inflamed tissues except for the CNS as it does not cross the blood-brain barrier even in the 
presence of inflamed meninges. Dosage adjustments will not be required even in severe hepatic or renal dysfunctions ${ }^{5}$.

Three unrelated groups of antimicrobial agents share the same ribosomal binding site in the bacterial cell- macrolides (erythromycin), lincosamides (clindamycin), and type $b$ streptogramins $\left(\mathrm{MLS}_{\mathrm{B}}\right)$. Therefore, it is possible that resistance to one group of antibiotics (macrolides) might predict resistance to the other groups. Resistance to erythromycin is used as an indicator of possible resistance to clindamycin ${ }^{6}$. Staphylococcus aureus resistance to macrolide can be mediated by

A) $m s r A$ gene coding for efflux mechanism

B) erm gene encoding for enzymes that confer inducible or constitutive resistance to $\mathrm{MLS}_{\mathrm{B}}$ antibiotics.

The most mechanism for acquiring resistance is through erm gene. In constitutive resistance erm gene will always produce r-RNA methylase. It provides resistance to both erythromycin and clindamycin in vivo as well as in vitro. It can be easily identified by using routine disk diffusion test. In inducible resistance r-RNA methylase is produced only in the presence of an inducing agent ${ }^{8}$. In such cases inducible resistance to clindamycin are difficult to detect in vitro by using routine laboratory as they appear resistant to erythromycin and sensitive to clindamycin. The treatment of patients harbouring $\mathrm{iMLS}_{\mathrm{B}}$ Staphylococci with clindamycin leads to the development of constitutive resistance, subsequently leading to therapeutic failure ${ }^{9}$.

Erythromycin is an effective inducer whereas clindamycin is a weak inducer. If inducible Clindamycin resistance in S. aureus can be reliably detected by D-test on a routine basis, Clindamycin can be safely and effectively used in patients with true Clindamycin susceptible strains $^{10}$. The laboratories and clinicians must be aware of local prevalence of iMLS $_{\mathrm{B}}$. From hospital to hospital prevalence of inducible clindamycin resistance may vary ${ }^{11}$. The present study is therefore undertaken to know the prevalence of inducible clindamycin resistance in our hospital as well as aware and aid our clinicians in using appropriate antibiotics to treat the infections of patients caused by Staphylococcus aureus in Khaja Banda Nawaz Teaching \& General Hospital, Kalaburagi.

The main objectives of this study includes to determine the prevalence of inducible clindamycin resistance in Staphylococcus aureus

\section{Materials and Methods}

This study was conducted at Microbiology laboratory of Khaja Banda Nawaz Teaching and General Hospital, attached to KBN institute of Medical Sciences, Kalaburagi for a period of one year i.e., from January 2018 to December 2018. Observational Cross Sectional Study was performed. Written informed consent was taken from the subject after explaining the nature of the study. This study was approved by ethical committee.

A total of 100 isolates of $S$. aureus were collected from various clinical specimens. Identification of Staphylococcus aureus was done as per standard guidelines ${ }^{12}$. Each isolate was subjected to the disk diffusion test for detection of MRSA as recommended by the CLSI ${ }^{10}$.

\section{Detection of inducible clindamycin resistance $^{10}$}

The isolates which were resistant to erythromycin were further studied for inducible clindamycin resistance by doing $\mathrm{D}$ 
test. Lawn culture of $S$. aureus isolates was prepared on Mueller-Hinton agar plate and standard discs of erythromycin $(15 \mu \mathrm{g})$ and clindamycin $(2 \mu \mathrm{g})$ were placed $15-26 \mathrm{~mm}$ apart and incubated at $37^{\circ} \mathrm{C}$ for $18-24$ hours.

Four different phenotypes were detected in Dtest which are as follows:

1. D test positive or Inducible $\mathrm{MLS}_{\mathrm{B}}$ phenotype: S. aureus isolates which were sensitive to clindamycin (zone size $\geq 21$ $\mathrm{mm}$ ) and resistant to erythromycin (zone size $\leq 13 \mathrm{~mm}$ ) and giving D shaped zone of inhibition around clindamycin disc with flattening towards erythromycin disc were taken as D test positive (Figure 1).

2. D test negative or MS Phenotype: S. aureus isolates which are sensitive to clindamycin (zone size $\geq 21 \mathrm{~mm}$ ) and resistant to erythromycin (zone size $\leq 13$ $\mathrm{mm}$ ) and giving circular zone of inhibition around clindamycin disc were taken as D test negative (Figure 2).

3. Constitutive $\mathrm{MLS}_{\mathrm{B}}$ phenotype: S. aureus isolates which showed resistance to both clindamycin (zone size $\leq 14 \mathrm{~mm}$ ) and erythromycin (zone size $\leq 13 \mathrm{~mm}$ )
(Figure 3).

4. S. aureus isolates which were sensitive to both erythromycin (zone size $\geq 23 \mathrm{~mm}$ ) and clindamycin (zone size $\geq 21 \mathrm{~mm}$ ). (Figure 4).

\section{Results and Discussion}

Cefoxitin disc sensitivity done on MuellerHinton agar revealed that 88 isolates were Methicillin Resistant Staphylococcus aureus (MRSA) and 12 were Methicillin Sensitive Staphylococcus aureus (MSSA) (Table 1).

Out of the $100 \mathrm{~S}$. aureus (88 MRSA; 12 MSSA) isolates, 30 (24 MRSA; 6 MSSA) isolates were susceptible to both erythromycin and clindamycin, 27 (24 MRSA; 3 MSSA) isolates showed constitutive MLSB resistance i.e., resistant to both erythromycin and clindamycin, 39 (36 MRSA; 3 MSSA) isolates showed inducible clindamycin resistance i.e., resistant to erythromycin and sensitive to clindamycin and showing D test positive and 4 (all from MRSA) isolates showed MS phenotype i.e., resistant to erythromycin and sensitive to clindamycin and showing D test negative (Table 2).

Table.1 Distribution of S. aureus based on Methicillin Sensitivity

\begin{tabular}{|l|l|}
\hline Methicillin Sensitivity & Frequency \\
\hline MRSA & 88 \\
\hline MSSA & 12 \\
\hline Total & $\mathbf{1 0 0}$ \\
\hline
\end{tabular}

Table.2 Erythromycin \& Clindamycin susceptibility pattern of $S$. aureus isolates

\begin{tabular}{|l|l|l|l|}
\hline Susceptibility pattern & MRSA & MSSA & Total \\
\hline E-S, CD-S & 24 & 06 & 30 \\
\hline E-R, CD-R (Constitutive MLS $_{\mathbf{B}}$ ) & 24 & 03 & 27 \\
\hline E-R, CD-S; D test positive (Inducible MLS $\left._{\mathbf{B}}\right)$ & 36 & 03 & 39 \\
\hline E-R, CD-S; D test negative (MS Phenotype) & 04 & 0 & 04 \\
\hline Total & $\mathbf{8 8}$ & $\mathbf{1 2}$ & $\mathbf{1 0 0}$ \\
\hline
\end{tabular}


Table.3 Erythromycin and Clindamycin susceptibility pattern of MRSA isolates

\begin{tabular}{|c|c|}
\hline Susceptibility pattern & MRSA \\
\hline E-S, CD-S & $24(27.3 \%)$ \\
\hline E-R, CD-R (Constitutive MLS $\mathbf{S}_{\mathrm{B}}$ ) & $24(27.3 \%)$ \\
\hline E-R, CD-S; D test positive (Inducible MLS $_{\mathbf{B}}$ ) & $36(40.9 \%)$ \\
\hline E-R, CD-S; D test negative (MS Phenotype) & $04(4.5 \%)$ \\
\hline Total & $88(100 \%)$ \\
\hline
\end{tabular}

Table.4 Various studies across India reporting the prevalence of Inducible Clindamycin Resistance in S. aureus

\begin{tabular}{|c|c|c|c|}
\hline \multirow[t]{2}{*}{ SI. No } & \multirow[t]{2}{*}{ Study Series } & \multicolumn{2}{|c|}{ Inducible Clindamycin Resistance } \\
\hline & & $\operatorname{MRSA}(\%)$ & $\operatorname{MSSA}(\%)$ \\
\hline 1. & Ciraj et al., ${ }^{17}$ & 38.4 & 12.9 \\
\hline 2. & Gadepalli et al., ${ }^{18}$ & 30 & 10 \\
\hline 3. & Shantala et al., & 32.5 & 15.53 \\
\hline 4. & Saikia et al., ${ }^{19}$ & 9.3 & 3.3 \\
\hline 5. & Deepak juyal et al., ${ }^{20}$ & 13.3 & 28.9 \\
\hline 6. & Dhanalakshmi et al., ${ }^{21}$ & 13.1 & 6 \\
\hline 7. & Amruth KU et al., ${ }^{6}$ & 35.33 & 11.74 \\
\hline 8. & Ajantha et al., ${ }^{22}$ & 74 & 45 \\
\hline 9. & Lall et al., ${ }^{23}$ & 37.1 & 6 \\
\hline 10. & Schreckenberger et al.,. ${ }^{24}$ & 7 & 20 \\
\hline 11. & Levin et al., ${ }^{25}$ & 12.5 & 68.5 \\
\hline 12. & Present study & 40.9 & 25 \\
\hline
\end{tabular}

Figure.1 D-test Positive (E-R, CD-S; Inducible MLS $\mathrm{B}_{\mathrm{B}}$ )

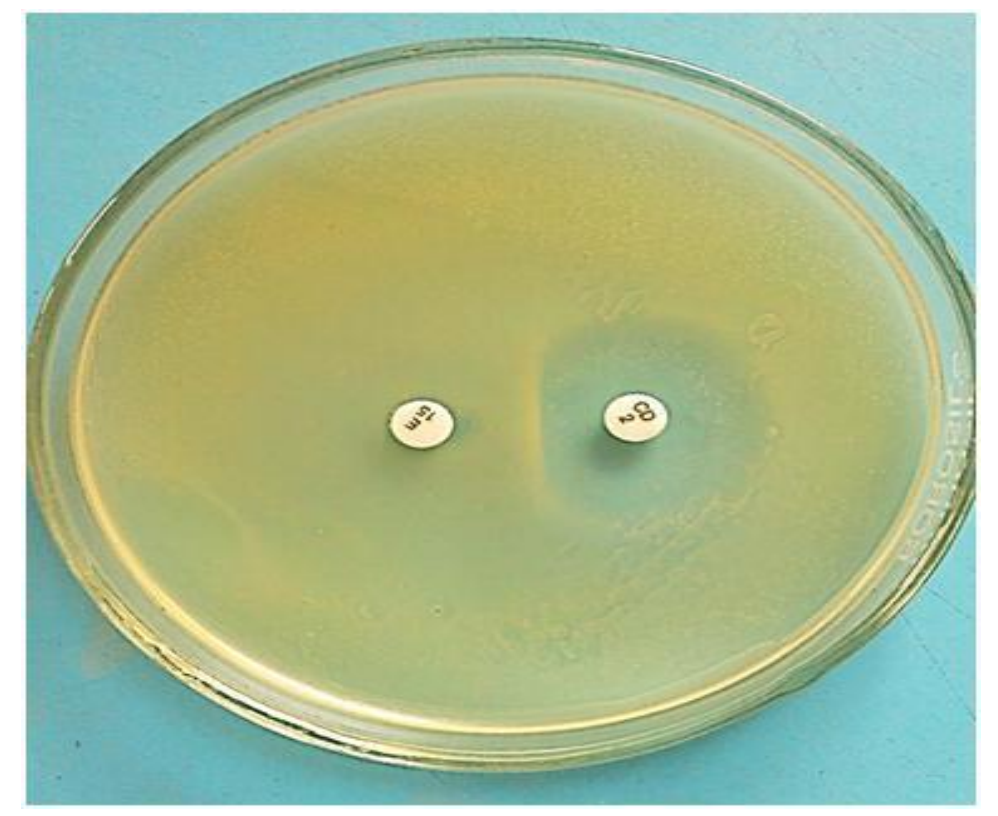


Figure.2 D-test Negative (E-R, CD-S; MS Phenotype)

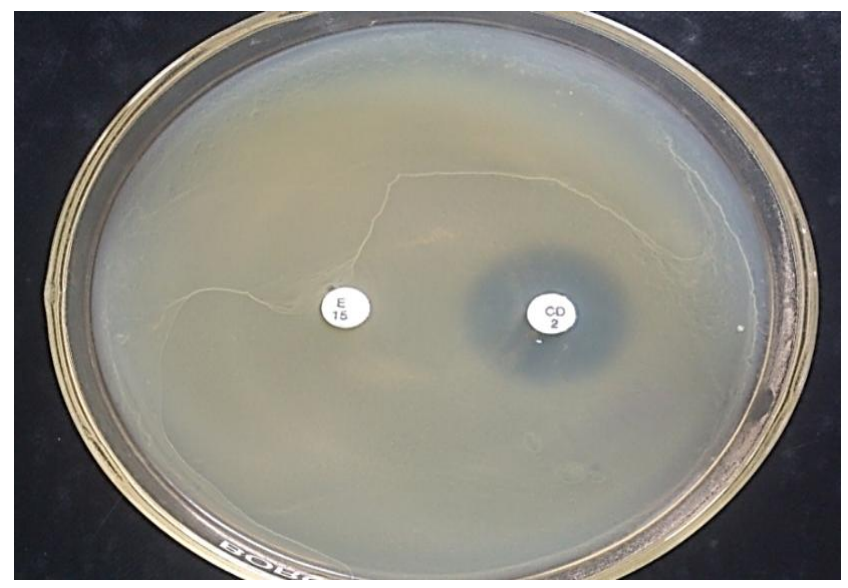

Figure. 3 Constitutive $\mathrm{MLS}_{\mathrm{B}}(\mathrm{E}-\mathrm{R}, \mathrm{CD}-\mathrm{R})$

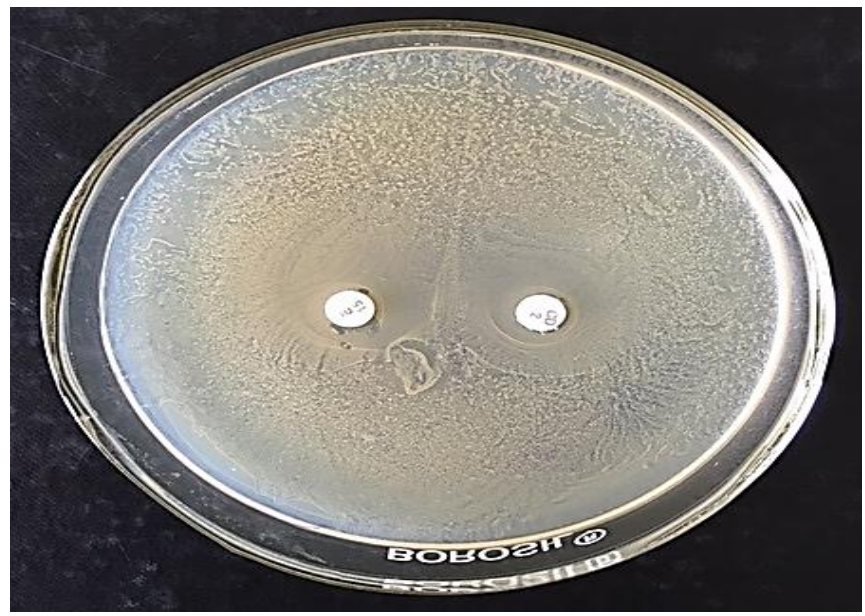

Figure.4 S. aureus sensitive to both Erythromycin and Clindamycin (E-S, CD-S)

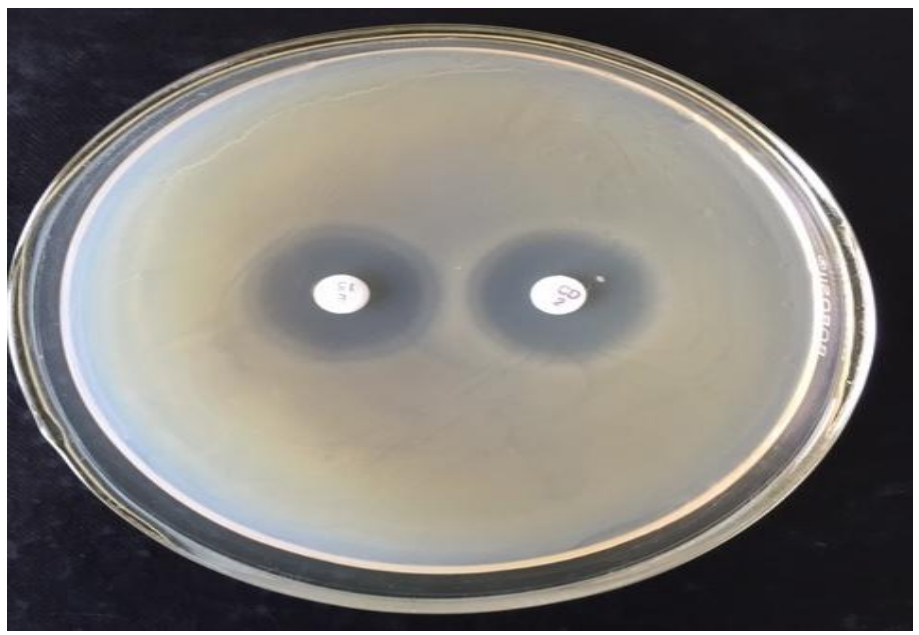


Out of the 88 MRSA isolates, 24(27.3\%) were susceptible to both erythromycin and clindamycin, $24(27.3 \%)$ showed constitutive $\mathrm{MLS}_{\mathrm{B}}$ resistance, $36 \% \quad(40.9 \%)$ showed inducible clindamycin resistance and 4 (4.5\%) showed MS phenotype (Table 3).

Our study revealed the prevalence of MRSA at Khaja Banda Nawaz Teaching and General Hospital to be $88 \%$ which is slightly higher than the findings observed by other workers like by Frazee et al., ${ }^{13}$ and Khanal et al., ${ }^{14}$ who reported $75 \%$ and $68 \%$ MRSA isolates respectively. This may be due to the indiscriminate and empirical use of antibacterial agents in our hospital. Our study findings are in contrast to findings observed by Kiran K Mokta et al., ${ }^{15}$ and Jyoti kumari et al., ${ }^{16}$ who reported only $23.42 \%$ and $30.2 \%$ MRSA isolates respectively.

Various workers have reported prevalence of Inducible Clindamycin Resistance among MRSA isolates varying from $9.3 \%$ to $74 \%$ and among MSSA isolates varying from $6 \%$ to $45 \%$ as shown in Table 4 .

Our study observed that out of 88 MRSA isolates, $36(40.9 \%)$ showed inducible clindamycin resistance and out of 12 MSSA isolates, $3(25 \%)$ showed inducible clindamycin resistance. In MRSA isolates both constitutive and inducible resistance phenotypes were found to be higher compared to MSSA.

Our study observed inducible clindamycin resistance of $40.9 \%$ in MRSA. Ciraj et al., ${ }^{17}$ reported 38.4\%, Amruth et al., ${ }^{6}$ reported $35.33 \%$ and Lall et al., ${ }^{23}$ reported $37.1 \%$ inducible clindamycin resistance in MRSA isolates. However our findings are in contrast with other studies conducted by Saikia et al. ${ }^{19}$ reported only $9.3 \%$ MRSA isolates with inducible clindamycin resistance and Ajantha et $a l .{ }^{22}$ who reported a high prevalence of
74\% inducible clindamycin resistance in MRSA isolates.

Our study also observed that percentage of inducible clindamycin resistance was higher amongst MRSA (40.9\%) as compared to MSSA (25\%). Yilmaz et al., ${ }^{5}$ (24.4\% in MRSA and $14.8 \%$ in MSSA), Gadepalli et al. ${ }^{18}$ (30\% in MRSA and $10 \%$ in MSSA) and Mohammed Rahbar et al., ${ }^{26}$ (22.6\% in MRSA and $4 \%$ in MSSA) reported higher percentage of inducible clindamycin resistance in MRSA as compared to MSSA. However our findings are in contrast with Schreckenberger et al., ${ }^{24}$ (7\% in MRSA and 20\% in MSSA) and Levin et al., ${ }^{25}$ (12.5\% MRSA and 68\% MSSA) who reported higher percentage of inducible clindamycin resistance in MSSA as compared to MRSA.

Our study observed constitutive resistance of $27.3 \%$ in MRSA isolates, however Angel et al., ${ }^{27}$ did not reported any of the strains.

Our study observed that out of 100 S. aureus (88 MRSA; 12 MSSA) isolates, 30 $\{24(27.3 \%)$ MRSA; 6(50\%) MSSA $\}$ were susceptible to both erythromycin and clindamycin, 27 \{24 (27.3\%) MRSA; 3(25\%) MSSA \} isolates showed constitutive MLS $_{B}$ resistance, 39 \{36 (40.9\%) MRSA; 3(25\%) MSSA $\}$ isolates showed inducible clindamycin resistance and 4 \{4(4.5\%) MRSA; 0(0\%) MSSA $\}$ isolates showed MS phenotype.

This observation suggest that checking for inducible clindamycin resistance is important, otherwise clindamycin therapy therapy would have been started due to misidentification of erythromycin resistant $S$. aureus isolates as clindamycin sensitive, ultimately leading to therapeutic failure. On the other hand, Clindamycin therapy is good therapeutic option in light of the restricted range of antibiotics available in those erythromycin 
resistant $S$. aureus isolates showing negative result for inducible clindamycin resistance. Thus in erythromycin resistant $S$. aureus isolates true Clindamycin sensitivity can only be judged after performing $D$ test

We conclude that whenever clindamycin is intended for $S$. aureus infection, the microbiology lab should tests the isolated organism for $\mathrm{iMLS}_{\mathrm{B}}$ by $\mathrm{D}$ test. $\mathrm{D}$ test is simple, inexpensive and easy to perform test. Clindmycin is drug of choice in case of D test negative isolates while it is not suitable for $\mathrm{D}$ test positive isolates.

\section{Acknowledgement}

We would like to thanks our patients to agree for giving the consent and our family members for their support.

\section{References}

1. Forbes BA, Sahm DF, Alice S, Weissfeld A, Baily W. Bailey and Scotts.Diagnostic Microbiology. Chapter 14. Staphylococcus, Micrococcus and similar organisms, $13^{\text {th }}$ Edition; Elsevier Mosby; 2014; 232-246.

2. Derek B, David E, Peter H, Donald M, Groffery R, Kevin $\mathrm{T}$ et al.,. Guidelines for the laboratory diagnosis and susceptibility testing for methicillin resistant Staphylococcus aureus. J Antimicrob chemother. 2005; 56(6):1000-1018.

3. Shantala GB, Shetty AS, Rahul RK, Vasudeva, Nagarathnamma T. Detection of inducible clindamycin resistance in clinical isolates of Staphylococcus aureus by the disc diffusion induction test. J Clin Diag Res 2011; 5(1):35-37.

4. Deotale V, Mendiratta DK, Raut U, Narang P. Inducible clindamycin resistance in Staphylococcus aureus isolated from clinical samples. Indian J Med Microbiol. 2010; 28(2):124-126.

5. Yilmaz G, Aydin K, Iskender S, Cayaln R, Koksal I. Detection and prevalence of inducible clindamycin resistance in Staphylococci. J Med Microbiol. 2007; 56(3):342-435.

6. Amruth KU, Sunilkumar B. Prevalence of inducible clindamycin resistance in Staphylococcus aureus in a tertiary care hospital in North-East Karnataka, India. Health sciences: An international journal 2011; 1(3): 21-24.

7. Leclercq R. Mechanisms of resistance to macrolides and lincosamides: Nature of the resistance elements and their clinical implications. Clin Infect Dis 2002; 34:48292.

8. Drinkovic D, Fuller ER, Shore KP, Holland DJ, Ellis-Pegler R. Clindamycin treatment of Staphylococcus aureus expressing inducible clindamycin resistance. J Antimicrob Chemother 2001; 48:315-6.

9. Siberry GK, Tekle T, Carroll K, Dick J. Failure of clindamycin treatment of methicillin-resistant Staphylococcus aureus expressing inducible clindamycin resistance in vitro. Clin Infect Dis 2003; 37: 1257-1260.

10. Clinical and Laboratory Standards Institute. Performance Standards for Antimicrobial Susceptibility Testing; Twenty-seventh Edition. CLSI document M100. Clinical and Laboratory Standards Institute, 940 West Valley Road, Suite 2500, Wayne, PA 19087 USA, Jan 2017.

11. Pal N, Sharma B, Sharma R, Vyas L. Detection of inducible clindamycin resistance among staphylococcal isolates from different clinical specimens in western India. Journal Postgrad Med 2010; 56(3):182-185.

12. Koneman WE, Allen SD, Janda WM, Schreckenberger PC, Winn Jr. WC, Procop G and Woods G (2006) The Gram positive cocci: Part I: Staphylococci and related organisms. In Koneman's Color Atlas and Textbook of Diagnostic Microbiology, 6th Edition, Lippincott Williams \& Wilkins, Philadelphia, New York, pp 623-671.

13. Frazee BW, Lynn J, Charlebois ED, Lambert L, Lowery D, Perdreau- 
Remington F. High prevalence of methicillin-resistant Staphylococcus aureus in emergency department skin and soft tissue infections. Ann Emerg Med. 2005; 45(3):311-320.

14. LK Khanal and BK Jha. Prevalence of Methicillin resistant Staphylococcus aureus (MRSA) among skin infection cases at a hospital in Chitwan, Nepal. Nepal Med Coll J 2010; 12(4): 224-228.

15. Kiran K. Mokta et al., Inducible Clindamycin Resistance among Methicillin Resistant and Methicillin Susceptible Strains of Staphylococcus aureus. Journal of Clinical and Diagnostic Research 2015; 9(8):20-23.

16. Jyoti Kumari, Shalini M. Shenoy, Shrikala Baliga, Chakrapani M. and Gopalkrishna K. Bhat. The cross-sectional study was conducted from February 2014 to February 2015 among four tertiary care hospitals in Mangalore, South India. Sultan Qaboos University Med J 2016; 16(2):175-181.

17. Ciraj AM, Vinod P, Sreejith G, Rajani K. Inducible clindamycin resistance among clinical isolates of staphylococci. Indian $\mathbf{J}$ Pathol Microbiol 2009; 52: 49-51.

18. Gadepalli R, Dhawan B, Mohanty S, et al.,. Inducible clindamycin resistance in clinical isolates of Staphylococcus aureus. Indian J Med Res 2006; 123:5713.

19. Saikia L, Nath R, Choudhary B, Sarkar M. Prevalence and antimicrobial susceptibility patten of methicillin resistant Staphylococcus aureus in Assam. Indian J Crit Care Med 2009; 13:156-158.

20. Deepak Juyal et al., The Prevalence of Inducible Clindamycin Resistance Among Staphylococci in a Tertiary Care Hospital A Study from the Garhwal Hills of Uttarakhand, India. Journal of Clinical and
Diagnostic Research 2013;7(1): 61-65.

21. Dhanalakshmi, et al.,. Prevalence of Inducible clindamycin resistance in Staphylococcus aureus. Journal of Academy of Medical Sciences 2012; 2(2):73-75.

22. Ajantha GS, Kulkarni RD, Shetty J, Shubhada C, Jain P. Phenotypic detection of inducible clindamycin resistance amongst Staphylococcus aureus isolates by using lower limit of recommended interdisk distance. Indian $\mathbf{J}$ Pathol Microbiol 2008; 51:376-378.

23. Lall M, Sahini AK. Prevalence of inducible clindamycin resistance of Staphylococcus aureus isolated from clinical samples. Medical J Armed Forces India. 2014; 70:43-47.

24. Schreckenberger PC, Ilendo E, Ristow KL. Incidence of constitutive and inducible clindamycin resistance in Staphylococcus aureus and coagulase negative staphylococci in a community and a tertiary care hospital. J Clin Microbiol 2004; 42:2777-2779.

25. Levin TP, Suh B, Axelrod P, Truant AL, Fekete T. Potential clindamycin Resistance in clindamycin-susceptible, erythromycinresistant Staphylococcus aureus: Report of a clinical failure. Antimicrob Agents Chemother 2005; 49:1222- 1224.

26. Rahbar M, Hajia M. Inducible clindamycin resistance in Staphylococcus aureus: A cross-sectional report. Pak J Biol Sci. 2007; 10:189-192.

27. Angel MR, Balaji V, Prakash JA, Brahmandathan KN, Mathews MS. Prevalence of inducible clindamycin resistance in gram positive organisms in a tertiary care centre. Indian J Med Micobiol 2008; 26:262-264.

\section{How to cite this article:}

Javeria Firdous and Basawaraj S. Patil. 2019. Study of Inducible Clindamycin Resistance in Staphylococcus aureus in a Tertiary Care Hospital. Int.J.Curr.Microbiol.App.Sci. 8(03): 14711478. doi: https://doi.org/10.20546/ijcmas.2019.803.171 